\title{
Nocturnal activity and the enuresis alarm device
}

\author{
A. H. CRISP \\ M.D., D.Sc., F.R.C.Psych. \\ L. I. SIRELING \\ M.B., L.R.C.P., M.R.C.Psych. \\ J. FAIZEY \\ S.R.N., R.M.N. \\ Academic Department of Psychiatry, St George's Hospital Medical School, Tooting, London SW17 ORE
}

\begin{abstract}
Summary
The effect on nocturnal activity of the wire mesh element within the 'buzzer and pad' enuresis alarm device was studied using healthy adult volunteers in a single or double cross-over design. On the nights when the mesh was in the bed there was less activity, supporting the finding of improved polygraphic sleep on the mesh and suggesting an unexpected therapeutic mechanism.
\end{abstract}

KEY WORD: sleep.

\section{Introduction}

Although the 'buzzer and pad' enuresis alarm device is a relatively safe, effective and widely-used treatment for nocturnal enuresis (Berg, 1981), its mode of action is difficult to explain on a classical learning model (Morgan, 1978). Crisp and Hafner (1974) studied nocturnal activity in an enuretic adult and found an inverse relationship between nocturnal activity and enuresis. They postulated that a component of the effect of the enuresis alarm device could be the increase in nocturnal activity resulting from discomfort due to lying on a pair of wire meshes. We report here a systematic study of the effect on nocturnal activity of lying on a pair of wire meshes, our hypothesis being that the motility score for the night would be increased under these conditions. A concurrent polysomnographic study was undertaken and is reported elsewhere (Sireling and Crisp, 1983). It revealed that sleep on the mesh was characterized by fewer sleep-stage shifts especially within light non-REM sleep and also by a reduction in light sleep and wakefulness.

\section{Methods}

The subjects comprised one female and 15 male volunteers aged 16-53 years, with no history of sleep difficulty or enuresis. On the appropriate nights the pair of wire meshes was arranged as if for use under the bottom sheet of the bed, connected to the alarm, the effect of which was demonstrated to eacis subject before the study. The alarm device adopted was the Eastleigh MOH 1 model used by tho Department of Child Psychiatry. Since polygraphif sleep recordings were also undertaken on certai $\bar{P}$ nights, subjects always slept with scalp electrode $\vec{S}$ attached.

The first eight subjects spent one night adapting toे the sleep laboratory, and were then randomly aboes cated in balanced pairs to spend the next four pairo of nights alternately with and without the mesh in plact. As a 'rebound' or 'carry-over' effect could not 30 ? excluded in the third and fourth pairs of nights, the remaining eight subjects were studied for only two pairs of nights in the same design, following two adaptation nights (Fig. 1).

Nocturnal activity was measured by means of $\overrightarrow{\vec{D}}$ motility bed (Crisp, Stonehill and Eversden, 1970) which provided a quantitative record of activity for each 5-min interval throughout the night. Scores for motility for the whole night were calculated on the basis of the first $6 \mathrm{hr}$ of the night, which was the maximum number of hours spent on the motility be by all subjects. The two-tailed Wilcoxon SignedRank Test was employed for statistical analysis. Duę to equipment failure, data were missing for 9 nights (out of a total of 96 recording nights) and on these occasions means have been calculated from the remaining nights' data.

\section{Results}

Because of concern about a possible 'carry-ove effect to the last 4 nights, the results for the first tw pairs of nights were examined separately. Signifis cantly less activity occurred on the nights when the mesh was in place (Table 1).

No difference was found between the last two pairs of nights: this lack of confirmation of the earlies 


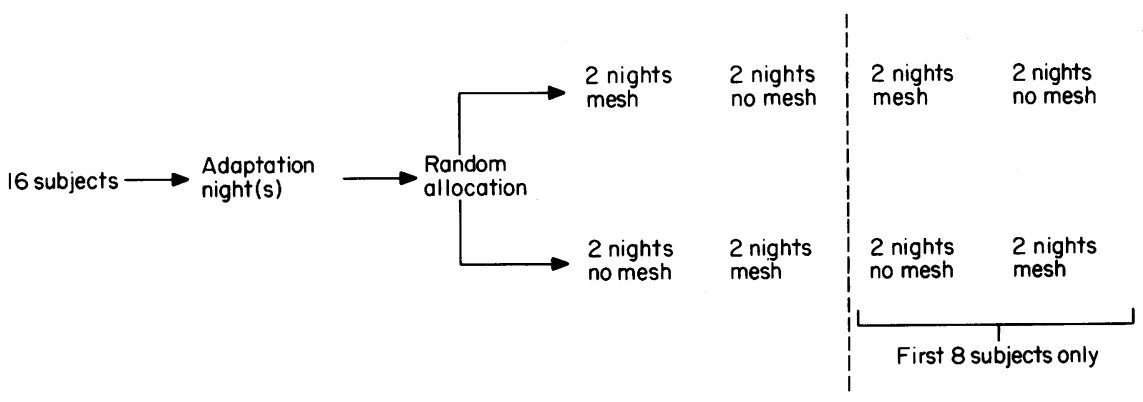

Fig. 1.

TABLE 1. Motility scores with and without the mesh in place [data for first two pairs of nights (means)]

\begin{tabular}{cccc}
\hline Subject & Mesh & No Mesh & Difference \\
\hline 1 & 957 & 762 & 195 \\
2 & 386 & 555 & -169 \\
3 & 544 & 973 & -429 \\
4 & 729 & 764 & -35 \\
5 & 776 & 1129 & -353 \\
6 & 393 & 452 & -59 \\
7 & 758 & 972 & -214 \\
8 & 615 & 891 & -276 \\
9 & 375 & 620 & -245 \\
10 & 360 & 314 & 45 \\
11 & 136 & 130 & 6 \\
12 & 116 & 72 & 44 \\
13 & 739 & 683 & 56 \\
14 & 145 & 218 & -73 \\
15 & 128 & 149 & -21 \\
16 & 680 & 1093 & -412 \\
Mean (s.d.) & $490(272)$ & $611(356)$ & $-121(184)$ \\
\hline
\end{tabular}

nights' findings could be attributable to a carry-over effect.

Analysis by hour of the night showed the greatest difference in the first hour, with lower motility on the mesh; this difference did not quite achieve statistical significance.

\section{Discussion}

It has been shown that when the wire meshes are in place, nocturnal activity decreases. This unexpected finding, the reverse of that proposed within the original hypothesis, correlates with the polygraphic evidence (Sireling and Crisp, 1983) that when the wire meshes are in place, there is less light sleep and it is less disturbed.

If the meshes have the same effect on the sleep of the enuretic patient as on our normal subjects, the earlier suggestion by Crisp and Hafner (1974) of a therapeutic effect mediated by increased restlessness could not be correct. The possibility of the reverse being the case, namely that by promoting a restful night's sleep the frequency of enuresis is reduced, is supported by evidence that at least in some patients nocturnal enuresis occurs predominantly in wakefulness (Ditman and Blinn, 1955; Ritvo et al., 1969) or light sleep (Schiff, 1965; Mikkelsen et al., 1980).

The design of the present study can shed no light on the mode of action by which sleep is improved in this paradoxical way. It may be that activity is reduced because it would be more uncomfortable to shift around than to lie still on a wire mesh. Alternatively, the extra firmness and support provided by the mesh might actually be more comfortable to sleep on than a soft and sagging or springbased mattress. Further research is now required to ascertain whether the presence of the 'buzzer' is necessary for the effect of the 'buzzer and pad' on normal sleep; also whether the 'pad' effect on such sleep is altered by the presence of scalp electrodes and related tethering.

\section{References}

BERG, I. (1981) Child psychiatry and enuresis. British Journal of Psychiatry, 139, 247.

CRISP, A.H. \& HAFNER, J. (1974) Nocturnal activity and enuresis: a study of a 35-year-old male. Journal of Neurology, Neurosurgery and Psychiatry, 37, 610.

CRISP, A.H., STONEHILL, E. \& EvERSDEN, I.D. (1970) The design of a motility bed including its calibration for the subject's weight. Medical and Biological Engineering, 8, 455.

Ditman, K.S. \& BLINN, K.A. (1955) Sleep levels in enuresis. American Journal of Psychiatry, 111, 913.

Mikkelsen, E.J., Rapoport, J.L., Nee, L., Groenau, C., MenDELSEN, W. \& GILlin, J.C. (1980) Childhood enuresis I. Sleep patterns and psychopathology. Archives of General Psychiatry, 37, 1139.

MORGAN, R.T.T. (1978) Relapse and therapeutic response in the conditioning treatment of enuresis: a review of recent findings on intermittent reinforcement, overlearning and stimulus intensity. Behaviour Research and Therapy, 16, 273.

Ritvo, E.R., ORnitz, E.M., GotTlieb, F., Poussaint, A.F., MARON, B.J., DitmanN, K.S. \& BlinN, K.A. (1969) Arousal and non-arousal enuretic events. American Journal of Psychiatry, 126, 77.

SCHIFF, S.K. (1965) The EEG, eye movements and dreaming in adult enuresis. Journal of Nervous and Mental Diseases, 140, 397.

SiRELING, L.I. \& CRISP, A.H. (1983) Sleep and the enuresis alarm device. Journal of the Royal Society of Medicine, 76, 131.

(Accepted 12 July 1983) 